Commentary on The Case of Sonia: Psychotherapy With a Complex, Difficult Patient Grounded in the Integrated Psychotherapy Model of Héctor Fernández-Álvarez

\title{
Complex and Difficult Clinical Patients: Reflections on Fernández-Álvarez's Integrative Psychotherapy Model as Applied to the Case of "Sonia"
}

\section{CLAUDIA CASTAÑEIRAS ${ }^{\text {a }}$ \& HÉCTOR FERNÁNDEZ-ÁLVAREZ ${ }^{\text {a,b }}$}

${ }^{a}$ AIGLE Foundation, Buenos Aires, Argentina

${ }^{\mathrm{b}}$ Correspondence regarding this article should be addressed to Héctor Fernández-Álvarez, AIGLE Foundation, Virrey Olaguer y Feliú 2679, (C1426EBE) Buenos Aires, Argentina.

Email: hfa@aigle.org.ar

\begin{abstract}
Fernández-Álvarez 's Integrative Psychotherapy Model (IP Model) is designed to be applied to complex and difficult clinical patients. Scherb (2014) and her professional team aptly applied the IP Model to one such client, "Sonia," who received a successful, multilevel, integrated treatment for 10 years. Scherb's case illustrates the IP Model by analyzing links among the conceptualization, psychopathology, diagnosis, treatment plan, and specific interventions in the case. Her case study reflects the consistency and versatility of the IP Model to account for the complexity of a case in a systematic manner, and provides specific clinical indicators for evaluating the process and outcome in a complex and difficult case such as Sonia's.
\end{abstract}

Keywords: complex patients; Fernández-Álvarez's Integrated Psychotherapy Model; borderline personality disorder; bipolar disorder; case study; clinical case study

\section{INTRODUCTION}

Approaching complex and/or difficult patients is a challenge for the body of theoretical, clinical, and technical knowledge currently available. Despite seeming to have increased in numbers considerably in recent decades, so-called difficult patients make up a population for which psychotherapy still shows limited response capacity (Najavits, 2001; Hanna, 2002; Castonguay \& Beutler, 2006; Barlow, 2010; Fernández-Álvarez, 2012). However, it is important to note that "complex" and "difficult" are not equivalent terms, although in many cases they present a high degree of correspondence and below we use them interchangeably (Hanna, 2002).

These patients are certainly a challenge for health systems. Their treatment has become particularly pressing since the 1990s, which is one of the central themes in the literature. Research has focused not only on understanding these difficult patients, but also on the selection 
of methods and techniques that provide greater effectiveness in clinical practice (Semerari, 2002, Fernández-Álvarez, 2010).

What defines a patient as complex is not restricted to the intrinsic, structural, and historical factors of the patient and his/her evolution, or meeting criteria for diagnostic categories. Outside relationships and circumstances surrounding therapy must also be taken into account. From this perspective, it may be more appropriate to refer to these clients as patients in difficult situations (Fernández-Álvarez, 2001). As part of this, the clinical complexity of patients in difficult situations is reflected by the depth and extent of the dimensions or levels involved, as well as the circumstances and contexts that enhance and maintain the disorder. This will regulate the process of making decisions about the treatment plan and the specific interventions, thereby achieving the best possible balance between the therapeutic goals, the means to achieve them, and the resources available.

Difficult patients are mainly characterized by complex dysfunction, a chronic course, unfavorable life contexts and life circumstances, high functional impairment and adjustment difficulties with negative consequences, high-risk exposure, and resistance to change. These features are clearly present in patients whose disorders involve borderline and other personality dysfunctions (Fernández-Álvarez, 2010, 2012).

Fernández-Álvarez 's Integrative Psychotherapy Model (IP Model; Fernández-Alvárez, 1992, 2001; Fernández-Álvarez et al., 2008) is designed to be applied to complex and difficult clinical patients. Elena Scherb's (2014) multilevel, integrated, 10-year-long therapy with Sonia is an excellent example of how the IP Model can successfully be applied to such a client. Below we describe the IP Model and how it played out as Scherb conducted the therapy with Sonia.

\section{BASES OF THE INTEGRATIVE PSYCHOTHERAPY MODEL}

The IP Model is part of the movement towards theoretical integration (Arkowitz, 1997). The model takes concepts from different theoretical approaches and formally organizes them into a theoretically higher-order structure. It includes contributions from psychodynamic, cognitivebehavioral, humanistic-existential, and systemic theories. The IP Model is systematized to address a wide variety of clinical situations. .

The IP Model is also based on principles (Beutler \& Harwood, 2000; Fernández-Álvarez, 2003) that guide the treatment plan and specific interventions for each clinical situation. These principles stress the importance of matching between patients and therapists to maximize the chance of therapeutic effectiveness (Wampold, 2001; Fernández-Álvarez, 2003; Corbella \& Botella, 2003).

Fernández-Álvarez (2003) considers three fundamental components that organize all therapeutic systems: (a) a theory of mind, (b) a psychopathological or dysfunctional experience model to explain the genesis and dysfunctional cycle of the disorder, and (c) a set of principles to promote therapeutic change to enable the recovery of the system's functionality. 
Regarding a theory of mind, the IP Model postulates the representational nature of the mind and the need to identify the way in which meanings are organized in the constructive experience of the patient (Fernández-Álvarez, 2006). The term "constructive” refers to the psychological and behavioral operations that are carried out by human beings as subjects of an ongoing, intense need to give meaning to their reality (Bruner, 1991). In this ongoing dynamic, in which unconscious processes are central, individuals need to organize the reality in which they live into a permanent representation of their world, including self-representation (FernándezÁlvarez, 1992). This representation is organized into structures that are developmental, progressive, and hierarchical and include both constructions of the self and strategies that guide interpersonal relationships (Fernández-Álvarez, 1992).

Regarding psychopathology, it follows from the IP Model that it is necessary to identify the deepest constructions involved in the patient's dysfunction, in order to establish the steps and resources needed for developing therapeutic goals and a treatment plan. The basis on which to explain the genesis of a mental disorder and the factors that sustain their durability is derived from the principle of multi-determinism, including: (a) biological, experiential, and sociocultural components, (b) the role of the self and interpersonal relationships, and (c) the involvement of current and historical factors in shaping a patient's distress (Fernández-Álvarez, 2003). In line with this formulation, the IP Model highlights the need to consider dimensions of personality as a basis for understanding dysfunctional processes and the relationships between behavior and experience (Fernández-Álvarez, 2010). Research has provided consistent data on the basic dimensions of personality linked to emotional disorders (Clark, Watson \& Mineka 1994; Rosellini \& Brown, 2011).

Finally, regarding a program of treatment, it is necessary to develop a program based on the principle of gradual changes. The therapist must always keep in mind that dysfunctional patterns, the more profound they are, the more reactant. The treatment program should include the variety of formats and procedures needed to address the diversity of demands and therapeutic goals, even more so regarding complex patients.

\section{PRINCIPLES THAT ORGANIZE THE APPLICATION OF THE MODEL}

The IP Model contains principles that guide and organize the implementation of treatment procedures, both independently and combined, according to the requirements of each clinical situation. The therapeutic plan is based on clinical interviews and psychological assessment. The latter explore the nature, extent, severity, and chronicity of the disorder. The IP Model also assesses and takes into account the urgency and phenomenology of a patient's distress, developmental and contextual factors, available social support network and resources, readiness to change, and the patient's expectations for therapy.

\section{CLINICAL AND DIAGNOSTIC CONSIDERATIONS}

Beyond their specific diagnosis, the clinical presentation of complex and difficult patients shows that their personal organization is dysfunctional. They present with both cognitive and 
behavioral impairments, which hinder their successful adjustment to interpersonal/relational contexts.

These patients are usually resistant to treatment, with frequent relapse. They report a history of ineffective treatments, often present with comorbid chronic problems and diagnoses that define them as severely disturbed and complex patients, and present with other problems that often include risky situations, difficulties in interpersonal relationships, and depletion or absence of support networks.

\section{AN ASSESSMENT OF SONIA}

Scherb (2014) presents Sonia through a case study in a natural context and describes in a systematic way the clinical decisions and interventions at each stage of the therapy process, a long process lasting 10 years with a high degree of complexity. At the beginning of treatment, Sonia was a 44-year-old, divorced woman who lived with her 18-year-old, moderately-retarded son. Sonia was functionally and economically dependent on her parents, unable to independently take care of herself or even to meet her basic needs. She had a history of previous hospitalizations caused by depressive symptoms and violent episodes. The referral arose from Sonia's refusal to be psychiatrically hospitalized again, along with a severely conflicted relationship with her family, on whom she depended and who combined both overprotection and rejection in relating to Sonia.

Sonia's behavioral instability and the dysregulation of her emotional states indicated borderline personality disorder and bipolar disorder. These diagnoses were partly explained by genetically based, temperamental vulnerability, by a deficit in appropriate skills to generate and maintain relationships over time, and by an impoverished and inconsistent representation of herself. The extent of Sonia's dysfunction made it necessary to develop a treatment plan that progressively included working on her personal reorganization to achieve more sustainable changes across time - that is, to aim at broader goals beyond symptomatic remission.

Sonia had chronic difficulties with the interpersonal relationships in her life (FernándezÁlvarez, 2010) and problems in the perception and interpretation of her self (Livesley, 2008). She presented with a core dysfunctional schema, involving a need to be accepted and loved in what she perceived to be a rejecting and invalidating world. Her personality disorder created significant additional problems in feeling comfortable with her self and in relating to her family and to others generally. Furthermore, she presented with comorbid clinical symptoms compatible with depression, difficulties in impulse control, trichotillomania, morbid obesity, impaired intellectual functioning, and a generalized maladaptive pattern, restricted to a limited repertoire of rigid behaviors, which is characteristic of personality disorders (Fernández-Álvarez, 2010).

In sum, Sonia's problems included a long history of negative experiences; a disabling context; a generalized pattern of affective instability; low self-esteem; clinically significant difficulty regulating emotional states and interpersonal relationships, particularly with her family; self-harm behaviors; problems in managing her impulsivity; and impaired cognitive processes, such as in her self-schema. 


\section{TREATMENT PLAN AND INTERVENTIONS}

There is a broad consensus (Belloch \& Fernández-Álvarez, 2002) that treating patients with serious personality disorders requires complex, multilevel, interdisciplinary interventions employing a broad technical repertoire (Semerari, 2002; Fernández-Álvarez, 2010). This can be seen in the case of Sonia, for whom the treatment plan included specific interventions at different levels by different professionals.

One of the goals Scherb set was to progressively change Sonia's living conditions to facilitate an increased sense of personal agency and to promote a new way of relating to her family. This is consonant with favoring gradual and accessible changes.

Patients such as Sonia often find it difficult to establish and maintain the therapeutic relationship. In these instances, the likelihood of a deficit in the therapeutic alliance is increased by a prolonged time of treatment, and a negative history of previous attempts at solution (Safran \& Muran, 2005). With this in mind, one of the first procedures that Scherb introduces while working with Sonia was directed to building a positive and strong therapeutic relationship. Scherb is directive but also flexible, showing tolerance for Sonia's mechanisms of resistance. At the same time, Scherb exhibits a high degree of motivation and interest in Sonia, as recommended for this type of clinical situation.

Scherb created a long-term treatment plan, based on combined procedures (psychotherapy, pharmacotherapy, therapeutic support, and social assistance) organized into five flexible stages. Her plan is consistent with the goal of the IP Model of having the patient progress from struggling with pathology to improving their general quality of life, including activating particular, positive patient resources that can help the patient manage their own life (Fernández-Álvarez, 2011). This may be observed both in the direction of Scherb's interventions and in the goals of the professional team, which sought to combine in the most effective way the available resources and to encourage Sonia's agency (Bandura,1989). This approach matches the consensus of clinicians with different theoretical approaches about the importance of using the resources of the patient for change (Hervás Vazquez Torres \& Valverde, 2009).

From the beginning of treatment, the focus was directed at modifying Sonia's dysfunctional relational pattern to help change her behavior, and thereby validate herself. Sonia's dysfunctional experience was expressed in two levels: first, in her subjective distress, and second, in the objective conditions that showed her functional impairment (such as daily financial management). The first treatment objective was generating a positive therapeutic relationship. Numerous investigations confirm its importance to the process and outcome of psychotherapy (Safran \& Muran, 2005; Semerari, 2002).

A review of the factors involved in the treatment of personality disorders indicates that the therapist's active involvement in the therapy and positive attachment to the patient are often sensitive indicators of the quality of treatment, although this has not yet been sufficiently investigated (Fernández-Álvarez, Clarkin, Salgueiro \& Critchfield, 2006). Among the therapist characteristics that predict positive outcome are: an open mind; a flexible and creative approach; 
comfort with long-term, emotionally intense relationships; tolerance of one's own negative feelings regarding the patient and treatment process; patience; training; and experience in personality disorders (Fernández-Álvarez et al., 2006). There are consistent findings on the relationship between the overall quality of the therapeutic alliance and outcome (Safran and Muran, 2005; Wampold, 2001). So far, there is strong evidence for the positive influence of the collaborative aspect of the therapeutic alliance in the therapeutic process and results. The IP Model highlights the interactional nature of the psychotherapeutic process, which takes place as an active and collaborative exchange and is attuned to each clinical situation.

As described above, Scherb developed a positive and strong therapeutic relationship with Sonia. This was designed in part to promote Sonia's participation in and responsibility for her improvement process, helping to increase her motivation and reinforcing positive actions directed to therapeutic change. In the case of patients like Sonia, this objective becomes particularly important, given the potential threats of alliance rupture in long-term treatments (Safran \& Muran, 2005).

The IP Model recommends three basic strategies for the therapeutic process: validation of the patient's experience, setting realistic goals, and gradual interventions. These are seen in Scherb's treatment plan, which provides five phases with specific objectives and duration of increasing complexity. Interventions executed using the IP Model begin with the most peripheral level changes and move toward changes in core patterns (Fernández-Álvarez, 2010). The treatment plan established two goals: to work on Sonia's development of coping and interpersonal skills, and to restructure Sonia's basic cognitions about herself.

In the initial phase, the work on the family system and social support, based on a psychoeducational component, sought to generate alternative and more adaptive modes of interaction. The team also worked to help Sonia develop skills in order to meet her basic needs and those of her child, and to increase her functional autonomy by changing her passive stance and sense of being a victim. Later on the treatment progressed towards reinforcing the gains related to Sonia's obesity, involving the allocation of basic patterns related to her father's rejection. Finally, relapse prevention sessions were included.

Scherb's case study details the therapeutic process and an assessment of outcome, which are very valuable in understanding the case. Scherb shared with the other therapy team members her therapy session recordings with Sonia, along with Sonia's periodic ratings on the "List of Problems and Behaviors Questionnaire" (LOPBQ). This sharing allowed Scherb to enhance the therapy team's understanding. The follow-up interview at the end of the last year of treatment indicated positive changes in adjustment in terms of Sonia's interpersonal relationships, her level of subjective distress, and her ability to maintain a healthy weight level.

The IP Model systematizes stages and specific actions for each phase of the treatment, including an assessment of the presenting problems, a full psychological assessment and diagnosis, and the subsequent development of a treatment plan and specific interventions. This process can be observed in detail in Sonia's case study, which included a treatment plan 
involving intensive individual psychotherapy; behavioral management; coaching and skill training; family therapy; and pharmacotherapy.

\section{CONCLUDING REMARKS}

Scherb's case study of Sonia documents and interprets a representative clinical treatment with complex patients. Scherb invites the reader to venture into the vicissitudes of the therapeutic journey with Sonia over 10 years. This type of naturalistic and longitudinal clinical case study sheds light on the complexity of clinical phenomena and the scope and limitations of current psychotherapy. As set forth in this commentary, integrated approaches seem particularly appropriate for these types of clinical situations, which seem in fact to be increasing in numbers and presenting many challenges to contemporary clinics.

Much has been accomplished, but much remains to be done in developing effective treatments for complex and difficult patients. Scherb's work is an important step in this direction.

\section{REFERENCES}

Arkowitz, H. (1997). Integrative theories of therapy. In P. L. Wachtel \& S.B. Messer (Eds.). Theories of psychotherapy. Origins and evolution (pp. 227-288). Washington: American Psychological Association.

Bandura, A. (1989). Human agency in social cognitive theory. American Psychologist, 44, 11751184.

Barlow, D. H. (2010). Negative effects from psychological treatments. American Psychologist, 63(1), 13-19.

Belloch, A., \& Fernández-Álvarez, H. (Comps.). (2002). Trastornos de la personalidad. Madrid: Síntesis.

Beutler, L. E., \& Harwood, T. M. (2000). Prescriptive psychotherapy. A practical guide to systematic treatment selection. Oxford: University Press.

Bruner, J. (1991). Actos de significado. Más allá de la revolución cognitiva. Madrid: Alianza Editorial.

Castonguay, L. G., \& Beutler, L. E. (2006). Common and unique principles of therapeutic change: What do we know and what do we need to know? In L.G. Castonguay \& L.E. Beutler (Eds.), Principles of therapeutic change that work (pp. 353-369). Oxford: Oxford University Press.

Clark, L. A., Watson, D., \& Mineka, S. (1994). Temperament, personality and the mood and anxiety disorders. Journal of Abnormal Psychology, 1, 103-116.

Corbella, S. y Botella, L. (2003). La alianza terapéutica: historia investigación y evaluación. Anales de psicología, 19, (2), 205-221.

Fernández-Álvarez, H. (1992). Fundamentos de un modelo integrativo en psicoterapia. Buenos Aires: Paidós.

Fernández-Álvarez, H. (2001). Fundamentals of an integrated model of psychotherapy (translated into English by A. L. LaBruzza). Northvale, NJ: Jason Aronson.

Fernández-Álvarez, H. (2003). Claves para la unificación de la psicoterapia (más allá de la integración). Revista Argentina de Clínica Psicológica, 12, 229-246. 
Fernández-Álvarez, H. (2006). La filosofía de la psicoterapia cognitiva: entre Descartes y Spinoza. Revista Argentina de Clínica Psicológica, 15(3), 193-201.

Fernández-Álvarez, H. (2010). Modelo integrativo de psicoterapia para los trastornos de la personalidad. En: A. Belloch Fuster y H. Fernández-Álvarez (Coords.). Tratado de Trastornos de la Personalidad (337-354). Madrid: Síntesis.

Fernández-Álvarez, H. (2010). Principios generales para la intervención en los trastornos de personalidad. En: Belloch Fuster y Fernández-Álvarez (Coords.).Tratado de trastornos de la personalidad (pp. 295-306). Madrid: Síntesis.

Fernández-Álvarez, H. (2011). Perspectiva de la psicoterapia. En Fernández-Álvarez (Comp.). Paisajes de la psicoterapia: Modelos, aplicaciones y procedimientos (pp.269-295). Buenos Aires: Polemos.

Fernández-Álvarez, H. (2012). Perturbaciones emocionales y disfunciones de la personalidad. En J. Obst Camerini (Comp.), Aportes del siglo XXI a las Terapias Cognitivas (pp. 93-108). Buenos Aires: Catrec Ediciones.

Fernández-Álvarez, H., Clarkin, J. F., Salgueiro, M. C., \& Critchfield, K. L. (2006). Participant factors in treating personality disorders. In L.G. Castonguay \& L.E. Beutler, Principles of therapeutic change that work (pp. 203-218). Oxford: Oxford University Press.

Fernández-Álvarez, H.; Pérez, A. y Fraga Míguez, M. (2008). Modelo de abordaje y diseño de tratamiento. En: Integración y Salud Mental (pp. 23-64). Bilbao: Desclée de Brouwer.

Hanna, F. J. (2002). Therapy with difficult clients. Using the precursors model to awaken change. Washington: American Psychological Association.

Hervás Torres, G., \& Vázquez Valverde, C. (2009). La ciencia del bienestar. Fundamentos de una psicología positiva. Madrid: Alianza Editorial.

Livesley, W. J. (2008). Integrated therapy for complex cases of personality disorder. Journal of Clinical Psychology: In Session, 64, 207-223.

Najavits, L. M. (2001). Helping “difficult” patients. Psychotherapy Research, 11(2) 131-152.

Rosellini, A. J., \& Brown, T. A. (2011). The NEO Five-Factor Inventory latent structure and relationships with dimensions of anxiety and depressive disorders in a large clinical sample. Assessment, 18 (1), 27-38.

Safran, J. D., \& Muran, J. C. (2005). La alianza terapéutica. Una guía para el tratamiento relacional. Bilbao: Desclée de Brouwer. In English: Negotiating the therapeutic alliance: A relational treatment guide (2003). New York: Guilford.

Scherb, E. (2014). The case of "Sonia": Psychotherapy with a complex, difficult patient grounded in the integrated psychotherapy model of Héctor Fernández-Álvarez. Pragmatic Case Studies in Psychotherapy, 10 (1), Article 1, 1-29. Available: http://hdl.rutgers.edu/1782.1/pcsp_journal

Semerari, A. (Ed.) (2002). Psicoterapia cognitiva del paciente grave. Bilbao: Desclée de Brouwer.

Wampold, B. E. (2001). The great psychotherapy debate: Models, methods, and findings. New York: Routledge. 